\title{
Mycorrhizal fungi and microalgae modulate antioxidant capacity of basil plants
}

\author{
Marieta Hristozkova ${ }^{1 *}$, Liliana Gigova ${ }^{2}$, Maria Geneva $^{1}$, Ira Stancheva ${ }^{1}$, Ivanina Vasileva ${ }^{2}$, \\ Mariana Sichanova ${ }^{1}$, Janet Mincheva ${ }^{1}$ \\ ${ }^{1}$ Laboratory "Plant-Soil Interactions", Institute of Plant Physiology and Genetics, Bulgarian Academy of Sciences, 1113 Sofia, \\ Bulgaria \\ ${ }^{2}$ Laboratory "Experimental Algology", Institute of Plant Physiology and Genetics, Bulgarian Academy of Sciences, 1113 Sofia, \\ Bulgaria
}

Vol. 57, No. 4: 417-426, 2017

DOI: 10.1515/jppr-2017-0057

Received: August 17, 2017

Accepted: November 27, 2017

*Corresponding address:

mhristozkova@abv.bg

\begin{abstract}
Mycorrhizal fungi, algae and cyanobacteria are some of the most important soil microorganisms and major components of a sustainable soil-plant system. This study presents for the first time evidence of the impact of green alga and cyanobacterium solely and in combination with arbuscular mycorrhizal fungi (AMF) on plant-antioxidant capacity. In order to provide a better understanding of the impact of AMF and soil microalgae on Ocimum basilicum L. performance, changes in the pattern and activity of the main antioxidant enzymes (AOEs), esterases and non-enzymatic antioxidants including phenols, flavonoids, ascorbate, and $\alpha$-tocopherols were evaluated. The targeted inoculation of $O$. basilicum with AMF or algae (alone and in combination) enhanced the antioxidant capacity of the plants and the degree of stimulation varied depending on the treatment. Plants in symbiosis with AMF exhibited the highest antioxidant potential as was indicated by the enhanced functions of all studied leaf AOEs: 1.5-, 2- and more than 10-fold rises of superoxide dismutase (SOD), glutathione-S-transferase (GST) and glutathione reductase (GR), respectively. The greatest increase in the total esterase activity and concentration of phenols, flavonoids and ascorbate was marked in the plants with simultaneous inoculation of mycorrhizal fungi and the green algae. 2,2-diphenyl-1-pycril-hydrazyl (DPPH) free radical scavenging method and ferric reducing antioxidant power (FRAP) assay proved the increased plant antioxidant capacity after co-colonization of green algae and mycorrhizae.
\end{abstract}

Key words: antioxidants, arbuscular mycorrhizal fungi, Ocimum basilicum L., soil microalgae

\section{Introduction}

Medicinal plants from the Lamiaceae family have been used since ancient times for their pharmaceutical properties (Bais et al. 2002) due to the secondary metabolites such as phenolic compounds (including flavonoids and phenylpropanoids) as well as anthocyanins (Phippen and Simon 2000). Sweet basil (Ocimum basilicum L.) belonging to the Lamiaceae family is a rich source of phenolic antioxidant compounds and flavonoids (Juliani and Simon 2002; Jayasinghe et al. 2003).
Soil-microbe-plant interactions are complex and there are many ways in which they can affect plant health and productivity. Many species belonging to the Lamiaceae family, including sweet basil, form a symbiotic association with arbuscular mycorrhizal fungi (AMF) (Wang and Qiu 2006). In addition to increasing the uptake of poorly available nutrients such as phosphorus and nitrogen (Toussaint et al. 2004) or providing protection against pathogens (Odeyemi et al. 2010; 
Ziedan et al. 2011), AMF can also cause changes in the accumulation of secondary metabolites, including phenolics, in host plant roots (Devi and Reddy 2002; Yao et al. 2003). Induction of specific manganese-dependent superoxide dismutase (Mn-SOD) isoforms observed in colonized parts of mycorrhizal tomato roots suggests that localized oxidative bursts might occur in the fungi (Pozo et al. 2002). However, it was reported that Glomus mosseae directly increases the essential oil content in shoots of Origanum sp. (Khaosaad et al. 2006) as well as sweet basil (Copetta et al. 2006). Reactive oxygen species (ROS) were initially thought as toxic by-products of aerobic metabolism. In recent years, it has been established that ROS play an important signaling role in the plants, controlling processes such as growth, development, response to biotic and abiotic environmental factors and programmed cell death. When ROS are at high concentrations they may initiate destructive oxidative processes such as chlorophyll bleaching, lipid peroxidation, protein oxidation, and damage to nucleic acids (Herbinger et al. 2002). To protect themselves from oxidative injury, higher plants induced effective antioxidant systems (Asada 1999). The antioxidant systems consist of antioxidant enzymes and non-enzymatic antioxidants including phenols, flavonoids, ascorbate, glutathione, and $\alpha$-tocopherols. Plant phenols show marked qualitative and quantitative variations not only at different genetic levels (between and within species and cultivars) but also between physiological and developmental stages (Bunning et al. 2010). They also vary in response to environmental factors, such as light intensity and nutrient availability (Yang et al. 2004; Mogren et al. 2007).

The beneficial effect of arbuscular mycorrhizal inoculation on plants is well known. Relatively little is known about the effects of AMF colonization and the addition algae on the antioxidant defense system in shoots of medicinal plants, which are often the harvest products.

Cyanobacteria and green algae release into the soil a large number of substances that play an important role in building up soil fertility, as well as acting as plant growth promoting agents, which results in increased productivity. These microorganisms contain growth-promoting regulators (auxin, gibberellic acid, and cytokinins), nutrients, sugar, amino acids, vitamins, and other secondary metabolites (Karthikeyan et al. 2007). Cyanobacteria, more commonly known as blue-green algae, are able to convert insoluble phosphorus in the soil into forms accessible to plants and some of them fix the atmospheric dinitrogen and convert it into a bioavailable form of ammonium (Sahu et al. 2012). Synechocystis sp. strain R10 was isolated from the shallow lake in Rupite, Bulgaria. The effect of light and temperature on growth, biochemical composition, enzymatic antioxidant defense and biological activity of Synechocystis sp. R10 (Gigova et al. 2012) was investigated. However, the role of microalgae as a plant antioxidant, especially in relation to their functioning in the rhizosphere, has not been explored in depth. Most research has focused on their growth promotion (influence on plant photosynthesis and yield). Due to the lack of information, the aim of the presented research was to evaluate the influence of AMF (Claroideoglomus claroideum EEZ 54) and mono-algal cultures (Scenedesmus incrassatulus R83 and Synechocystis sp. $\mathrm{R} 10)$ in the soil on the antioxidant capacity of basil (O. basilicum) plants.

\section{Materials and Methods}

\section{Biological materials and growth conditions}

Basil plants (O. basilicum var. purpurascens Benth.) were grown from seeds in $2 \mathrm{~kg}$ transparent plastic boxes (five plants per box for each treatment) of polyethylene glycol terephthalate (PET) with $92 \%$ transmittance in the range of 380-710 $\mathrm{nm}$ in a growth chamber from May to September under a light intensity of $320 \mu \mathrm{mol} \cdot \mathrm{m}^{-2} \cdot \mathrm{s}^{-1}$ at $21-25^{\circ} \mathrm{C}$ (night-day) and a $15 \mathrm{~h}$ photoperiod. The relative humidity ranged from 40 to $65 \%$. The plants developed on a soil : perlite substrate $(3: 1, \mathrm{v} / \mathrm{v})$. All pots were adjusted daily to $60 \%$ water holding capacity. The soil (leached cinnamonic forest soil - Chromic Luvisols, FAO - 30-40 cm depth) had the following agrochemical characteristics: $\mathrm{pH}\left(\mathrm{H}_{2} \mathrm{O}\right)-6.2$; $8 \mathrm{mg} \cdot \mathrm{kg}^{-1}$ soil total mobile nitrogen $\left(\mathrm{N}-\mathrm{NO}_{3}{ }^{-}+\mathrm{N}-\mathrm{NH}_{4}^{+}\right)$; $30 \mathrm{mg} \cdot \mathrm{kg}^{-1}$ soil $\mathrm{P}_{2} \mathrm{O}_{5} ; 120 \mathrm{mg} \cdot \mathrm{kg}^{-1}$ soil $\mathrm{K}_{2} \mathrm{O}$.

The mycorrhizal strain (C. claroideum, ref. EEZ 54) was kindly provided by the AMF collection of Estación Experimental del Zaidín (CSIC Granada, Spain). Mycorrhizal inoculation was done by placing the seeds over a thin layer of the AMF inoculum $\left(2 \mathrm{~g} \cdot \mathrm{kg}^{-1}\right.$ soil substrate) following the layering method of Jackson et al. (1972). The inoculum consisted of colonized roots and soil from 4-month-old oat pot cultures.

Algae strains came from the culture collection of the Experimental Algology Department (Institute of Plant Physiology and Genetics, Bulgarian Academy of Sciences). Monoalgal cultures of Scenedesmus incrassatulus R83 and Synechocystis sp. R10 were grown autotrophically in a medium according to Šetlik (1967), modified by Georgiev et al. (1978) with a $1 / 2$ concentration of nutrients and mineral medium after Aiba and Ogawa (1977), respectively. The final concentration of algal suspensions used for watering was $0.5 \mathrm{~g} \cdot \mathrm{l}^{-1}$. The algae were maintained and prepared for watering of basil plants with uninterrupted illumination from luminescent lamps $\left(75 \mu \mathrm{mol} \cdot \mathrm{m}^{-2} \cdot \mathrm{s}^{-1}\right.$ light intensity), and bubbling with $3 \mathrm{~cm}^{3} \cdot \mathrm{s}^{-1}$ air, enriched with $0.5 \% \mathrm{CO}_{2}$ (Petkov 1995). Algal suspension for 
inoculation was added twice after seed germination instead of watering with sterilized water (Petkov 1995).

Six treatments were compared: 1 - control noninoculated plants $(\mathrm{C}) ; 2$ - plants, inoculated with C. claroideum EEZ 54(AM); 3 - plants, inoculated with S. incrassatulus R83 (AL1); 4 - plants, inoculated with Synechocystis sp. R10 (AL2); 5 - plants, inoculated with C. claroideum EEZ 54 and S. incrassatulus R83 (AM + AL1); 6 - plants, inoculated with C. claroideum EEZ 54 and Synechocystis sp. R10 (AM + AL2).

\section{Native polyacrylamide gel electrophoresis (PAGE) and enzyme activity staining}

Fresh leaves $(0.50 \mathrm{~g}$ FW) from plants exposed to different treatments were homogenized in $0.1 \mathrm{mM} \mathrm{K}$-phosphate buffer ( $\mathrm{pH} 7.8$ ), containing $2.0 \mathrm{mM}$ disodium ethylenediaminetetraacetate dihydrate ( $\mathrm{Na}_{2}$-EDTA), $1 \mathrm{mM}$ phenyl methyl sulfonyl fluoride (PMSF), 2\% polyvinylpyrrolidone K-40 (w/v) and 10\% glycerol. The homogenates were centrifuged at $12000 \times g$ for $30 \mathrm{~min}$. Both steps were carried out at $0-4^{\circ} \mathrm{C}$. The concentration of soluble protein in the supernatants was measured by the dye-binding assay (Bradford 1976) with bovine serum albumin grade V (Sigma) as a standard. For determination of changes in the isoenzyme profile and activities of superoxide dismutase (SOD, EC 1.15.1.1), glutathione-S-transferase (GST, EC 2.5.1.18), glutathione-reductase (GR, EC 1.6.4.2) and esterase (EST, EC 3.1.1.x), equal amounts ( $35 \mu \mathrm{g})$ of leaf proteins were subjected to discontinuous PAGE under nondenaturing, nonreducing conditions essentially as described by Laemmli (1970), but without sodium dodecyl sulfate (SDS). Electrophoretic separation was performed by using $4 \%$ and $10 \%$ polyacrylamide in the stacking and resolving gels, respectively, for $4-5 \mathrm{~h}$ at a constant current of $35 \mathrm{~mA}$ per gel. After completion of electrophoresis, separate gels were stained for the activities of the respective enzymes.

Bands of SOD activity were localized on gels as described by Azevedo et al. (1998). The gels were soaked in $0.1 \mathrm{mM}$ nitroblue tetrazolium, $0.05 \mathrm{mM}$ riboflavin, and $0.3 \%(\mathrm{v} / \mathrm{v})$ tetramethyl ethylene diamine (TEMED) in $50 \mathrm{mM}$ potassium phosphate buffer ( $\mathrm{pH}$ 7.8) for $20 \mathrm{~min}$ in the dark. The gels were then placed in distilled water and exposed to a light box until they became uniformly blue, while bands where SOD was present were achromatic (10-15 min). The metalloforms of SOD were identified by staining parallel gels preincubated for 30 min with selective inhibitors $(2 \mathrm{mM} \mathrm{KCN}$ for inhibiting $\mathrm{Cu} / \mathrm{ZnSOD}$ and $5 \mathrm{mM} \mathrm{H}_{2} \mathrm{O}_{2}$ for inhibiting both $\mathrm{Cu} / \mathrm{ZnSOD}$ and FeSOD (Azevedo et al. 1998).

Glutathione reductase activity was detected by incubating the gels in $250 \mathrm{mM}$ Tris- $\mathrm{HCl}$ buffer ( $\mathrm{pH} 7.8$ ), containing $0.24 \mathrm{mM}$ 3-(4,5-dimethylthiazol-2-yl)-2, 5-diphenyltetrazolium bromide (MTT), $0.34 \mathrm{mM}$ 2,6-dichlorophenolindophenol (DPIP), $3.6 \mathrm{mM}$ oxidized glutathione (GSSG), and $0.4 \mathrm{mM}$ reduced form of nicotinamide adenine dinucleotide phosphate (NADPH) in darkness for $1 \mathrm{~h}$ (Anderson et al. 1995).

For GST activity staining, the method described by Ricci et al. (1984) was used. Briefly, after the electrophoretic run, the gel was equilibrated in $100 \mathrm{mM}$ potassium-phosphate buffer, $\mathrm{pH} 6.5$, for $10 \mathrm{~min}$, and transferred to a reaction mixture containing $4.5 \mathrm{mM}$ glutathione (GSH), $1 \mathrm{mM}$ 1-chloro-2,4-dinitrobenzene (CDNB), and $1 \mathrm{mM}$ nitroblue tetrazolium (NBT) in $0.1 \mathrm{M}$ potassium-phosphate buffer, $\mathrm{pH} 6.5$, at $37^{\circ} \mathrm{C}$ for $10 \mathrm{~min}$. Further, the gel was incubated at room temperature in $100 \mathrm{mM}$ Tris/ $\mathrm{HCl}, \mathrm{pH} 9.6$, containing $3 \mathrm{mM}$ phenazine methosulphate (PMS). The activity band appeared as an achromatic zone against a blue background.

Esterase isoforms and activity were visualized by staining the gels with $\alpha$-naphthyl acetate $(0.06 \%$, dissolved in a few drops of acetone) and Fast blue BB $(0.1 \%)$ in $200 \mathrm{mM}$ Tris ( $\mathrm{pH} 7.0)$ with gentle shaking at room temperature until black bands appeared (Murphy et al. 1996).

\section{Determination of total phenolic compounds and flavonoids}

Dry leaf samples ( $1 \mathrm{~g}$ ) were ground and thoroughly extracted with $96 \%$ (v/v) methanol. Concentrations of phenolic compounds were determined spectrophotometrically using the Folin-Ciocalteu reagent and calculated as caffeic acid equivalents (Pfeffer et al. 1998). Flavonoids in plant tissues were measured spectrophotometrically according to Zhishen et al. (1999), using the standard curve of catechin.

\section{Antioxidant potential assay}

Spectrophotometric quantification of water-soluble (WS-AOC) and lipid-soluble (LS-AOC) antioxidant capacity, expressed as equivalents of ascorbate and a-tocopherol, were performed through the formation of the phospho-molybdenum complex (Prieto et al. 1999). The assay was based on the reduction of Mo (VI) to Mo (V) by the sample analysis and the subsequent formation of a green phosphate/Mo (V) complex at an acidic pH. Dry leaf material (0.5 g) was ground with pestle and mortar to a fine powder and $3 \mathrm{ml} \mathrm{d \textrm {H } _ { 2 }} \mathrm{O}$ was added and the suspension was homogenized, transferred to tubes and shaken for $1 \mathrm{~h}$ at room temperature in the dark. The suspension was filtered and the extraction repeated with $3 \mathrm{ml} \mathrm{dH}_{2} \mathrm{O}$. The pel-

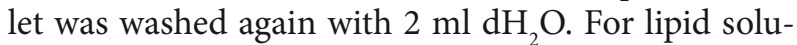
ble antioxidant capacity (expressed as a-tocopherol), the procedure was the same except that the extraction was carried out with hexane as a solvent. The method was optimized and characterized on linearity interval, repeatability and reproducibility and molar absorption 
coefficients for the quantitation of water-soluble and lipid-soluble antioxidant capacities expressed as equivalents of ascorbate and a-tocopherol (Prieto et al. 1999). Absorption coefficients were: $(3.4 \pm 0.1) \times 103 \mathrm{M}^{-1} \cdot \mathrm{cm}^{-1}$ for ascorbic acid and $(4.0 \pm 0.1) \times 103 \mathrm{M}^{-1} \cdot \mathrm{cm}^{-1}$ for a-tocopherol.

\section{Ferric reducing antioxidant power (FRAP) assay}

The FRAP reagent was freshly prepared by mixing acetate buffer $(300 \mathrm{mM}, \mathrm{pH}$ 3.6), TPTZ (tripyridyltriazine) solution (10 $\mathrm{mM}$ TPTZ in $40 \mathrm{mM} \mathrm{HCl}$ ), and $\mathrm{FeCl}_{3} \cdot 6 \mathrm{H}_{2} \mathrm{O}(20 \mathrm{mM})$ at a ratio of $10: 1: 1$ (Benzie and Strain 1996). To perform the assay, $900 \mu \mathrm{l}$ of FRAP reagent, $90 \mu \mathrm{l}$ of distilled water and $30 \mu \mathrm{l}$ of the leaf extract were mixed and incubated at $37^{\circ} \mathrm{C}$ for $15 \mathrm{~min}$. The absorbance was measured at $595 \mathrm{~nm}$ using FRAP working solution as a blank.

\section{Total antioxidant capacity}

Free radical-scavenging activity in leaf tissues was determined from the bleaching of the purple methanol solution (2, 2-diphenyl-1-pycril-hydrazyl, DPPH*), according to Tepe et al. (2006). DPPH• is a stable radical with a maximum absorption at $517 \mathrm{~nm}$ that can readily undergo reduction by an antioxidant. The percent inhibition of the $\mathrm{DPPH}^{\bullet}$ radical (I\%) was calculated by the following equation:

$$
\mathrm{I} \%=\left[\left(\mathrm{A}_{\text {blank }}-\mathrm{A}_{\text {sample }}\right) / \mathrm{A}_{\text {blank }}\right] \times 100,
$$

where: $A_{\text {blank }}$ - the absorbance of the control reaction (containing all reagents except the test compound), $\mathrm{A}_{\text {sample }}$ - the absorbance of the test compound.

\section{Statistical analysis}

The experiment had a completely randomized block design with four replications. The data were subjected to one-way analysis of variance (ANOVA) for comparison of means, and significant differences were calculated according to Fisher's least significance difference (LSD) test at the 5\% significance level using a statistical software package (Statgraphics Plus, version 5.1 for Windows). Data are presented as means \pm standard error.

\section{Results}

This study focused on the impact of AMF and microalgae on $O$. basilicum performance, changes in the pattern and activity of the main antioxidant enzymes, esterases and non-enzymatic antioxidants including phenols, flavonoids, ascorbate, and a-tocopherols. Seven common bands of SOD activity were detected in leaf protein samples from plants exposed to treatments (Fig. 1A, a). Band numbers 1 and 2 were identified as Mn-SOD enzymes by their insensitivity to inhibition by both $\mathrm{H}_{2} \mathrm{O}_{2}$ (Fig. 1A, b) and cyanide (Fig. 1A, c), while band numbers 3 to 7 were sensitive to both inhibitors, suggesting that they represented a CuZnSOD activity. FeSOD activity was not detected in O. basilicum L.

Compared to the control untreated plants (C), the relative total activity of SOD, the first enzyme which scavenges reactive oxygen species, did not change after combined treatment with C. claroideum EEZ 54 and S. incrassatulus $\mathrm{R} 83$ ( $\mathrm{AM}+\mathrm{AL} 1)$, while the activity was higher in plants treated only with $\mathrm{AM}$, and lower
A

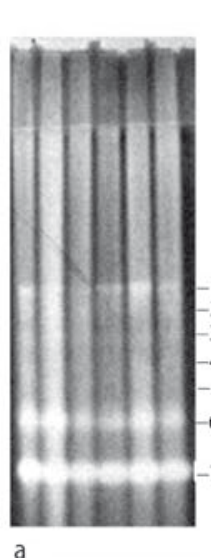

123456
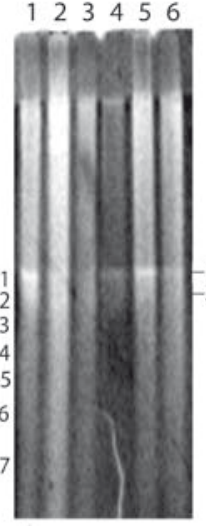

b

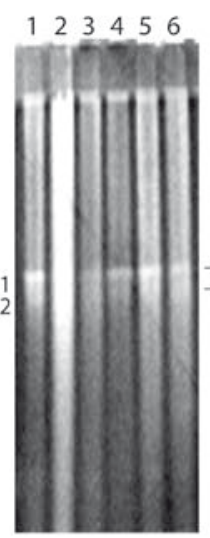

c
B

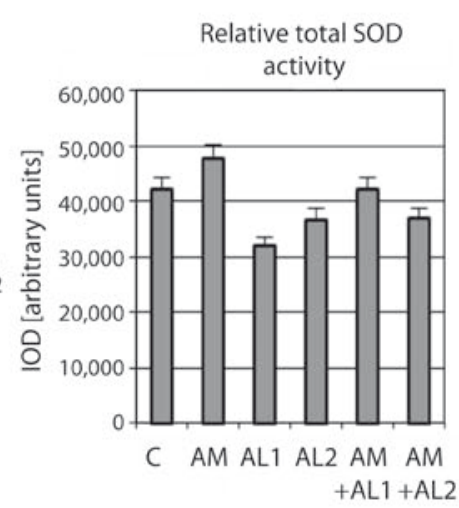

C

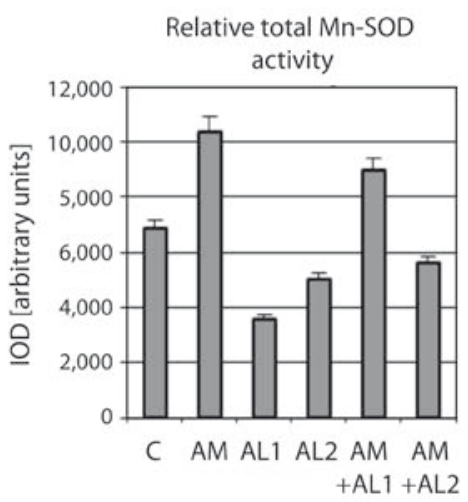

Fig. 1. Activity of superoxide dismutase (SOD) of non-inoculated (control) and inoculated (AMF and/or algae) Ocimum basilicum plants. In a gel SOD isoforms (A) pattern and intensity (a), identification of Mn-SOD (b), and identification of CuZnSOD (c) in leaves after native PAGE of the samples: lane 1- control untreated plant (C); $2-A M ; 3-A L 1 ; 4-A L 2 ; 5-A M+A L 1 ; 6-A M+A L 2$. Equal amounts of protein $(35 \mu \mathrm{g})$ were loaded per well. The isoforms of SOD are numbered from cathode to anode. SOD1 and SOD2 represent Mn-SOD; and SOD3 to 7 - CUZnSOD activity. Relative total SOD activity (B) and total activity of MnSOD (C) of the same samples expressed as a sum of the values (in arbitrary units) for integrated optical density (IOD) of the respective bands. Results shown are representative of three independent trials 
in plants treated with AL1 (Fig. 1B). Application of Synechocystis sp. R10 alone and in combination with C. claroideum EEZ 54 (AL2; AM + AL2) slightly lowered the total SOD activity. The same trend of changes was observed in total Mn-SOD activity (Fig. 1C), but the increase and decrease were more pronounced, reaching $50 \%$ in both cases. Mn-SOD was also more responsive to the AM + AL1 treatment (about 30\% rise).

Four well-resolved bands of GR were detected in O. basilicum leaf extracts, following all treatments. Despite the similarity in GR patterns (Fig. 2A), the activity of this enzyme varied between the treatments. In control (C), AL2 and AM + AL1 treated plants, a relatively low total GR activity was maintained
(Fig. 2B). In AL1, AM + AL2 and AMF treatments, a gradual increase in enzyme activity was observed (by 200,346 and $1150 \%$, respectively).

GST was presented by seven isoforms (Fig. 3A). All treatments, except AL1, led to an increase in total activity from $148 \%$ for AM + AL2 to $288 \%$ for AL2, mainly due to stimulation of isoforms 3, 4, 5 and 6 (Fig. 3B).

Five esterase enzymes with a capacity to hydrolyze non-specific ester substrates such as $\boldsymbol{\alpha}$-naphthyl acetate were visualized on native polyacrylamide gels. The EST2 and EST4 were the most intense in all samples (Fig. 4A). Although the intensity of each band varied between treatments, relative total EST activity (Fig. 4B) increased or decreased slightly (in the range of 10 to
A

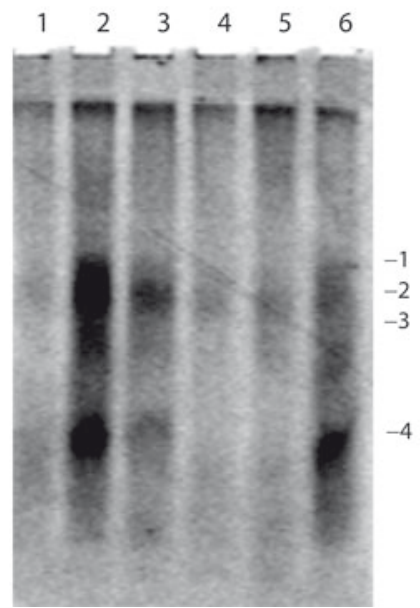

B

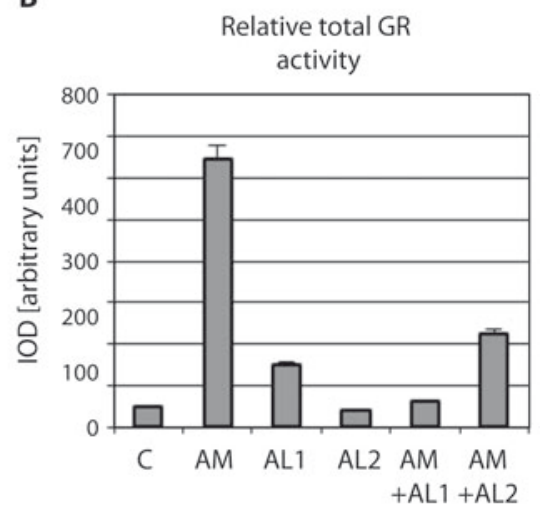

Fig. 2. Glutathione reductase (GR) activity of non-inoculated (control) and inoculated (AMF and/or algae) Ocimum basilicum plants. In a gel GR isoform pattern (A) and intensity in leaves after native PAGE of the samples (B): lane 1 - control untreated plant (C); 2 - AM; 3 - AL1; $4-A L 2 ; 5-A M+A L 1 ; 6-A M+A L 2$. Relative total GR activity of the same samples expressed in arbitrary units. Results shown are representative of three independent trials

A

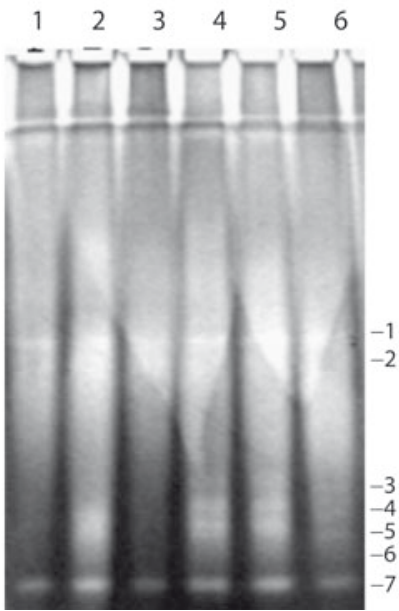

B

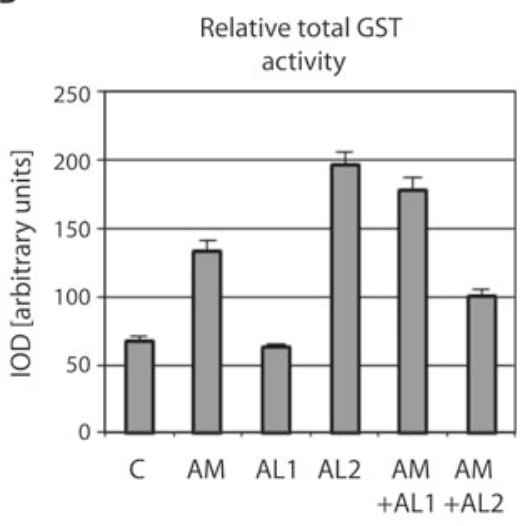

Fig. 3. Glutathione-S-transferase (GST) activity of non-inoculated (control) and inoculated (AMF and/or algae) Ocimum basilicum plants. In a gel GST isoform pattern (A) and intensity in leaves after native PAGE of the samples (B): lane 1 - control untreated plant (C); 2 - AM; $3-A L 1 ; 4-A L 2 ; 5-A M+A L 1 ; 6-A M+A L 2$. Relative total GST activity of the same samples expressed in arbitrary units. Results shown are representative of three independent trials 
A

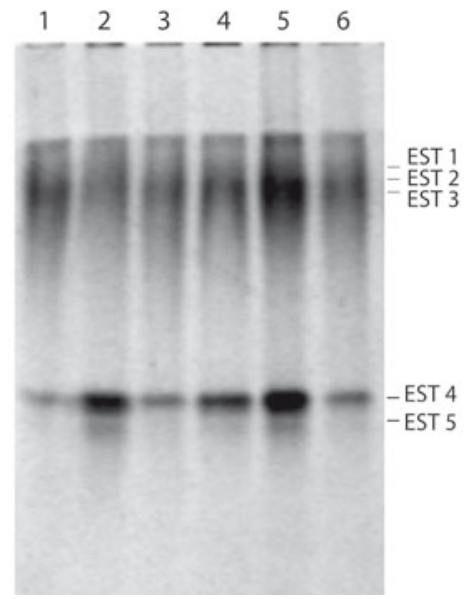

B

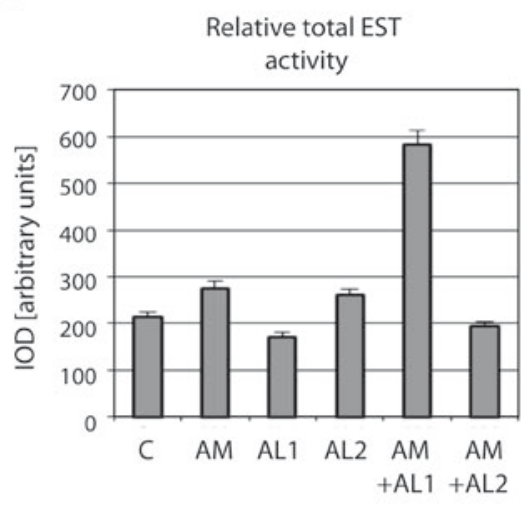

Fig. 4. Esterase (EST) activity of non-inoculated (control) and inoculated (AMF and/or algae) Ocimum basilicum plants. In a gel EST isoform pattern (A) and intensity in leaves after native PAGE of the samples (B): lane 1 - control untreated plant (C);2-AM; 3-AL1;4-AL2; $5-A M+A L 1 ; 6-A M+A L 2$. Relative total EST activity of the same samples expressed in arbitrary units. Results shown are representative of three independent trials

$30 \%$ ) compared to that of control plants (accepted for $100 \%)$. Only AM + AL1 treated plants showed significantly higher total enzyme activity (274\%). It should be noted, however, that slow (EST1 to 3) and faster (EST4 and 5) moving enzyme forms behaved differently. The slow moving ESTs showed a drop in activity (except for AM + AL1 treatment) in a narrow range (63-88\% from that of the control), while the activity of the faster moving EST4 and EST5 was increased. The relative total EST4 + EST5 activity was lowest in the control (accepted for 100\%) and highest in the AM + AL1 plants (1064\%). AM and AL2 treatments also markedly elevated the activity (by about 600 and $320 \%$, respectively). Comparatively less stimulation was observed in the AL1 and AM + AL2 treated plants (by 54 and 60\%, respectively).

Green algae showed more impact on total phenol content than cyanobacterium (Fig. 5). The content of total phenol compounds in nonmycorrhizal and mycorrhizal plants was less when they were treated with cyanobacterium (AL2; AM + AL2) in comparison with treatment with green algae (AL1; AM + AL1). The greatest flavonoid content rise was marked in the plants with tandem inoculation of mycorrhizal fungi and algae (AM + AL1; AM + AL2) while the lowest concentration was detected in control variant.

The content of lipid soluble metabolites with antioxidant capacity expressed as $\boldsymbol{\alpha}$-tocopherol in basil plants significantly increased with AMF treatment (Fig. 5) followed by inoculation with green alga solely (AL1) and in combination with AMF (AM + AL1). Water soluble-AOC increased with the addition of AMF together with microalgae. Basil plants treated with cyanobacterium solely (AL2) had less WSAOC (Fig. 5). Total phenols, WS-AOC and LS-AOC contents in mycorrhizal plants are higher when they are treated with green algae (AM + AL1), in comparison when they are treated with a cyanobacterium $(\mathrm{AM}+\mathrm{AL2})$. The antioxidant capacities measured by DPPHandFRAP methodsinbasilplants decreasedinthe control compared with inoculated treatments (Fig. 5). Green microalgae (AL1; AM + AL1) in the soil led to the highest antioxidant capacities in the basil leaves. Targeted treatments with cyanobacterium (AL2; $\mathrm{AM}+\mathrm{AL} 2$ ) had lower FRAP and DPPH values (Fig. 5).

\section{Discussion}

Soil organisms play a crucial role in the functioning of agricultural ecosystems. Mycorrhizal fungi, algae, and cyanobacteria are some of the most important soil microorganisms and major components of a sustainable soil-plant system. This study presents for the first time evidence of the impact of green alga and cyanobacterium solely and in combination with AMF on plant antioxidant activity. In order to get a better understanding of the impact of AMF and soil microalgae on O. basilicum performance, the changes in the pattern and activity of the main antioxidant enzymes, esterases and non-enzymatic antioxidants including phenols, flavonoids, ascorbate, and a-tocopherols were evaluated.

Our results showed that the treatments of $O$. $b a$ silicum with AMF or algae (alone and in combination) stimulated the antioxidant capacity of the plants and the degree of stimulation varied depending on the treatment. Moreover, the effect of each treatment was due to activation of specific antioxidant enzymes. 

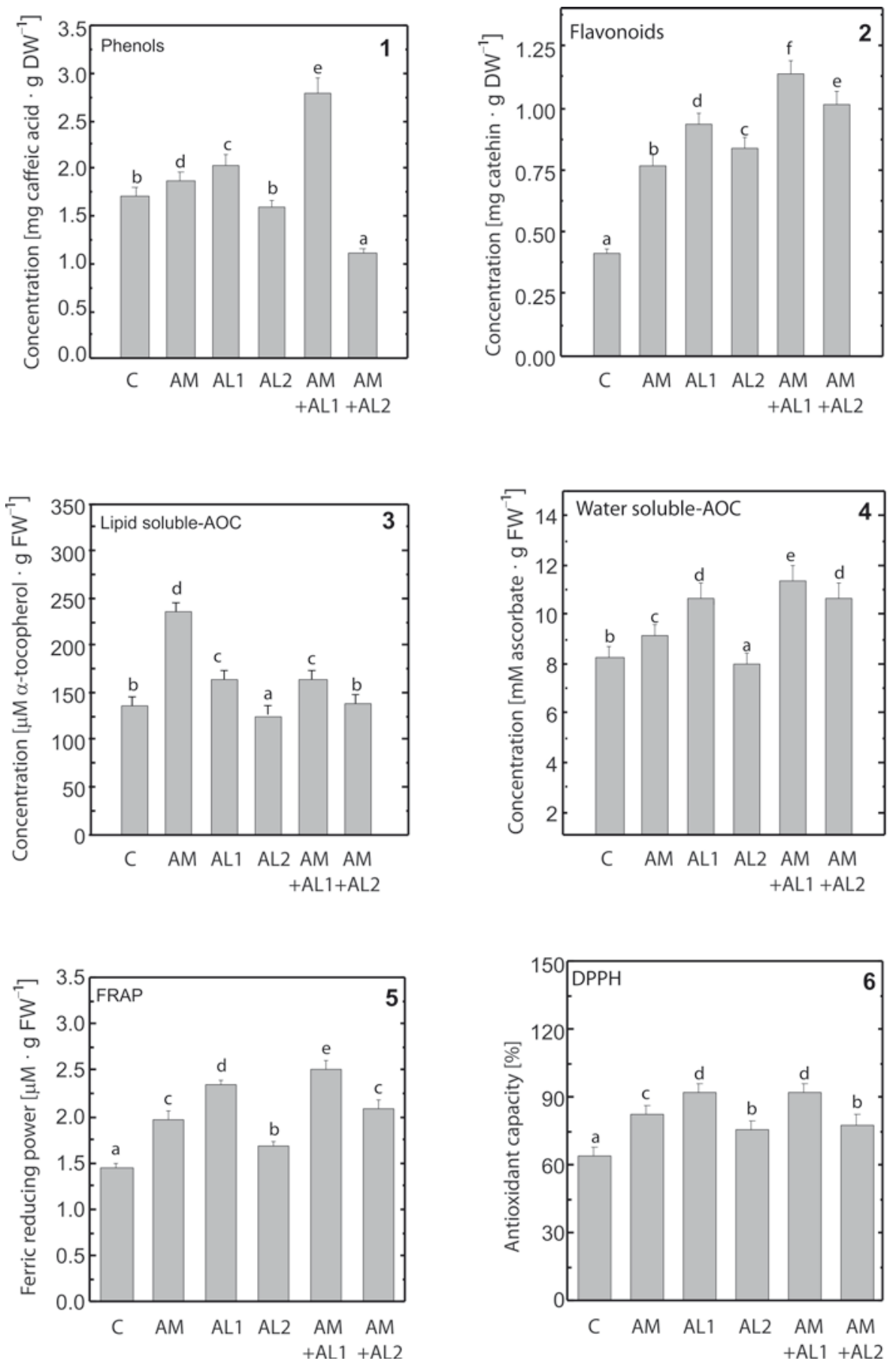

Fig. 5. Total phenolic (1), flavonoid concentrations (2), lipid-soluble (3), water-soluble antioxidant capacities (AOC) (expressed as equivalents of ascorbate and a-tocopherol) (4), ferric reducing antioxidant power (FRAP) (5) and free radical-scavenging activity (DPPH) (6) of non-inoculated (control, C) and inoculated (AMF and/or algae) Ocimum basilicum plants. FW - fresh weight, $\mathrm{DW}-$ dry weight. Values are means $\pm \mathrm{SE}$. Letters in common within a graph indicate no significant differences assessed by Fisher LSD test $(p \leq 0.05)$ after performing ANOVA $(n=9)$

Plants treated with AMF exhibited the highest antioxidant potential as was indicated by the enhanced functions of all studied leaf AOEs (1.5-, 2- and more than 10 -fold rises of Mn-SOD, GST and GR, respectively). In the AM + AL1 treated plants the activities of MnSOD and especially of GST were stimulated (by about 30 and $160 \%$, respectively), while in the AM + AL2 plants the activities of both GR and GST were higher than the control. AL1 treatment stimulated the activity of GR by about three times. GST was the only positive responder to the AL2 treatment. When applied alone, the algae apparently had less effect and this was probably related to the lack of direct contact between them and plants. When basil plants are double inocu- 
lated with C. claroideum EEZ 54 and S. incrassatulus $\mathrm{R} 83(\mathrm{AM}+\mathrm{AL} 1)$ or Synechocystis sp. R 10 (AM + AL2) however, the activity of plant enzymes differed from that after AMF only inoculation, suggesting that algae impact the AMF.

While being extensively studied primarily in the roots, a rise of the antioxidant status in the aboveground plant parts has been reported in different AM-inoculated plants compared to non-mycorrhizal plants. For example, higher levels of antioxidant enzyme activities were observed in leaves of tomato plants colonized by Glomus mosseae (Abdel Latef and Chaoxing 2011). According to Rozpądek et al. (2014), SOD activity measured in Cichorium intybus L. significantly increased in AMF inoculated plants, compared to non-inoculated plants. Estrada et al. (2013) also found that AMF symbiosis induced SOD and CAT activities of maize shoots and roots, emphasizing that the degree of induction depended on the AMF species. Despite the symbiotic nature of AMF associations, enhancement of AOEs functions may be a result of general plant defense response to fungal colonization.

In earlier reports, stimulation of leaf esterase activity was observed in duckweed (Lemna minor) exposed to lead, cadmium, chromium, zinc, copper and mercury (Mukherjee et al. 2004) and also in Centaurea ragusina under salt treatments (Radić and PevalekKozlina 2010). In these studies, the authors imply that the induction of esterases confers tolerance of plants to the applied treatments. Furthermore, plant esterases are known to actively participate in many biological processes, such as activation of signal molecules (Stuhlfelder et al. 2004), regulation of cell growth and organ development (Gao et al. 2009) as well as regulation of secondary metabolite levels and bioactivity (Dogru et al. 2000; Ganjewala and Luthra 2009). Based on this knowledge, it is tempting to speculate that the activated specific esterases (EST4 and EST5) of O. basilicum participate in the improvement of plant growth and development observed following all treatments (data not shown).

Some antioxidants are high molecular weight proteins and enzymes, while others are small molecular weight compounds such as phenols. Their antioxidant properties are associated with their ROS scavenging potential (Sakihama and Yamasaki 2002). Phenolic production in plants can be affected by biotic and abiotic factors (Toussaint et al. 2007). AMF colonization and microalgae treatment may be a way to alter or enhance phenolic production or composition within the host plant. It is also known that the accumulation of phenols in plants is dependent on the developmental stage of the symbiosis (Abdel-Lateif et al. 2012). In the present study, these compounds were analyzed in the advanced stage of mycorrhiza formation. The total phenols of $O$. basilicum are increased, when plants are inoculated with AMF and green algae (Fig. 5). Similar results for the phenol content have already been reported for several other mycorrhized plants (Jurkiewicz et al. 2010; Zubek et al. 2015). Phenolic compounds may play a key role in the crosstalk between plants and symbiotic fungi, as they affect spore germination, the growth of hyphae and stimulate root colonization (Abdel-Lateif et al. 2012; Pusztahelyi et al. 2015). There is a lack of studies on whether the microalgae have some role for phenols and flavonoids synthesis in plants. The contents of total phenols in aerial parts of basil do not change significantly when the plants are mycorrhized (Hazzoumi et al. 2015). Our results indicate that basil antioxidant potential mainly defined by its high concentration of phenolic compounds and flavonoids. These results confirm previous reports showing that total phenols and flavonoids contributed significantly to the antioxidant capacity in the plants of Lamiaceae (Matkowski et al. 2008).

\section{Conclusions}

The present study provides evidence that dual inoculation can be a simple and useful method for obtaining higher contents of total phenols, flavonoids and water soluble antioxidants followed by an increase of antioxidant activity in O. basilicum. The production of higher yield and quality in medicinal plants, through conventional methods, often requires external inputs such as fertilizers and pesticides. In this context, the use of bioinoculants, a natural alternative to chemical fertilizers, is likely to promote the production of active ingredients.

More detailed studies are needed, however, to clarify the exact role of mycorrhizal fungi in increasing the antioxidant activity and regulation of defense responses of the host plant. On the other hand, AMF has been found to improve resistance to pathogens, heavy metals and salinity, and influence the level of secondary metabolites in plants (Abdel Latef and Chaoxing 2011; Estrada et al. 2013; Zubek et al. 2015; Mollavali et al. 2016). With this in mind, it cannot be ruled out that the increase in antioxidant capacity is a prerequisite for better tolerance of the plants to subsequent abiotic and/or biotic stress.

AM associations bring about significant changes in the host plant and its environment: at the rhizosphere level, they influence soil structure, carbon deposition in the soil, and microbial diversity, in part through changes in root exudation. These shifts in the microbial communities of the rhizosphere may indirectly influence the outcome of plant interactions with other organisms, including soil microalgae. 


\section{Acknowledgements}

The authors would like to thank Madlen Boychinova, for her technical assistance.

\section{References}

Abdel Latef A.A.H., Chaoxing H. 2011. Effect of arbuscular mycorrhizal fungi on growth, mineral nutrition, antioxidant enzymes activity and fruit yield of tomato grown under salinity stress. Scientia Horticulturae 127 (3): 228-233. DOI https://doi.org/10.1016/j.scienta.2010.09.020

Abdel-Lateif K., Bogusz D., Hocher V. 2012. The role of flavonoids in the establishment of plant roots endosymbioses with arbuscular mycorrhiza fungi, rhizobia and frankia bacteria. Plant Signaling and Behavior 7 (6): 636-641. DOI: https://doi.org/10.4161/psb.20039

Aiba S., Ogawa T. 1977. Assessment of growth yield of a bluegreen alga: Spirulina platensis in axenic and continuous culture. Journal of General Microbiology 102: 179-182.

Anderson M., Prasad T., Stewart C. 1995. Changes in isozyme profiles of catalase, peroxidase, and glutathione reductase during acclimation to chilling in mesocotyls of maize seedlings. Plant Physiology 109 (4): 1247-1257. DOI: https:// doi.org/10.1104/pp.109.4.1247

Asada K. 1999. The water-water cycle in chloroplasts: scavenging of active oxygens and dissipation of excess photons. Annual Review of Plant Physiology and Plant Molecular Biology 50 (1): 601-639. DOI: https://doi.org/10.1146/annurev. arplant.50.1.601

Azevedo R., Alas R., Smith R., Lea P. 1998. Response of antioxidant enzymes to transfer from elevated carbon dioxide to air and ozone fumigation, in the leaves and roots of wildtype and catalase-deficient mutant of barley. Physiologia Plantarum 104 (2): 280-92.

Bais H., Walker T., Schweizer H., Vivanco J. 2002. Root specific elicitation and antimicrobial activity of rosmarinic acid in hairy root cultures of Ocimum basilicum. Plant Physiology and Biochemistry 40 (11): 983-995. DOI: https://doi. org/10.1016/s0981-9428(02)01460-2

Benzie I., Strain J. 1996. The ferric reducing ability of plasma (FRAP) as a measure of "antioxidant power": The FRAP assay. Analytical Biochemistry 239 (1): 70-76. DOI: https:// doi.org/10.1006/abio.1996.0292

Bradford M. 1976. A rapid and sensitive method for the quantification of micrograms quantities of protein utilising the principle of protein-dye binding. Analytical Biochemistry 72 (1-2): 248-254. DOI: https://doi.org/10.1006/ abio.1976.9999

Bunning M., Kendall P., Stone M., Stonaker F., Stushnoff C. 2010 Effects of seasonal variation on sensory properties and total phenolic content of 5 lettuce cultivars. Journal of Food Science 75 (3): 156-161. DOI: https://doi.org/10.1111/j.17503841.2010.01533.x

Copetta A., Lingua G., Berta G. 2006. Effects of three AM fungi on growth, distribution of glandular hairs, and essential oil production in Ocimum basilicum L. Var. Genovese. Mycorrhiza 16 (7): 485-494. DOI: https://doi.org/10.1007/s00572 006-0065-6

Devi M., Reddy M. 2002. Phenolic acid metabolism of groundnut (Arachis hypogaea L.) Plants inoculated with VAM fungus and Rhizobium. Plant Growth Regulation 37 (2): 151-156. DOI: https://doi.org/10.1023/A:1020569525965

Dogru E., Warzecha H., Seibel F., Haebel S., Lottspeich F., Stockigt J. 2000. The gene encoding polyneuridine aldehyde esterase of monoterpenoid indole alkaloid biosynthesis in plants is an ortholog of the alpha/ $\beta$ hydrolase super family. European Journal of Biochemistry 267 (5): 1397-1406. DOI: https://doi.org/10.1046/j.1432-1327.2000.01136.x
Estrada B., Aroca R., Barea J.M., Ruiz-Lozano J.M. 2013. Native arbuscular mycorrhizal fungi isolated from a saline habitat improved maize antioxidant systems and plant tolerance to salinity. Plant Science 201-202: 42-51. DOI: https://doi. org/10.1016/j.plantsci.2012.11.009

Ganjewala D., Luthra R. 2009. Geranyl acetate esterase controls and regulates the level of geraniol in lemongrass (Cymbopogon flexuosus Nees ex Steud.) mutant cv. GRL-1 leaves. Zeitschrift für Naturforschung 64 (3-4): 251-259. DOI: https://doi.org/10.1515/znc-2009-3-417

Gao Z., Qian Q., Liu X., Yan M., Feng Q., Dong G., Liu J., Han B. 2009. Dwarf 88, a novel putative esterase gene affecting architecture of rice plant. Plant Molecular Biology 71 (3): 265-276. DOI: https://doi.org/10.1007/s11103-009-9522-x

Georgiev D., Dilov H., Avramova S. 1978. Millieu nutritif tamponne et méthode de culture intensive des microalgues vertes [Buffered nutrient medium and intensive method of green microalgae cultivation]. Hydrobiology 7: 14-23. (in Bulgarian)

Gigova L., Gacheva G., Ivanova N., Pilarski P. 2012. Effects of temperature on Synechocystis sp. R10 (Cyanoprocaryota) at two irradiance levels. I: Effect on the growth, biochemical composition and defense enzyme activities. Genetics and Plant Physiology 2 (1-2): 24-37.

Hazzoumi Z., Moustakime Y., Elharchli E., Amrani K. 2015. Effect of arbuscular mycorrhizal fungi (AMF) and water stress on growth, phenolic compounds, glandular hairs, and yield of essential oil in basil (Ocimum gratissimum L). Chemical and Biological Technologies in Agriculture 2 (1): 10. DOI: https://doi.org/10.1186/s40538-015-0035-3

Herbinger K., Tausz M., Wonisch A., Soja G., Sorger A., Grill D. 2002. Complex interactive effects of drought and ozone stress on the antioxidant defense systems of two wheat cultivars. Plant Physiology and Biochemistry 40 (6-8): 691-696. DOI: https://doi.org/10.1016/s0981-9428(02)01410-9

Jackson N., Franklin R., Miller R. 1972. Effects of vesicular-arbuscular mycorrhizae on growth and phosphorus content of three agronomic crops. Soil Science Society of America 36 (1): 64-67. DOI: https://doi.org/10.2136/sssaj1972.0361 $5995003600010014 \mathrm{x}$

Jayasinghe C., Gotoh N., Aoki T., Wada S. 2003. Phenolics composition and antioxidant activity of sweet basil (Ocimum basilicum L.). Journal of Agricultural and Food Chemistry 51 (15): 4442-4449. DOI: https://doi.org/10.1021/jf034269o

Juliani R., Simon J.E. 2002. Antioxidant activity of basil. p. 575-579. In: "Trends in New Crops and New Uses" (J. Janick, A. Whipkey, eds.). ASHS Press, Alexandria, VA.

Jurkiewicz A., Ryszka P., Anielska T., Waligórski P., Białońska D., Góralska K., Tsimilli-Michael M., Turnau K. 2010. Optimization of culture conditions of Arnica montana L.: effects of mycorrhizal fungi and competing plants. Mycorrhiza 20 (5): 293-306. DOI: https://doi.org/10.1007/s00572-009-0280-z

Karthikeyan N., Prasannaa R., Nainb L., Kaushik B.D. 2007. Evaluating the potential of plant growth promoting cyanobacteria as inoculants for wheat. European Journal of Soil Biology 43 (1): 23-30. DOI: https://doi.org/10.1016/j. ejsobi.2006.11.001

Khaosaad T., Vierheili H., Nell M., Zitterl-Eglseer K., Novak J. 2006. Arbuscular mycorrhiza alters the concentration of essential oils in oregano (Origanum sp., Lamiaceae). Mycorrhiza 16 (6): 443-446. DOI: https://doi.org/10.1007/s00572006-0062-9

Laemmli U.K. 1970. Cleavage of structural proteins during the assembly of the head of bacteriophage T4. Nature 227 (5259): 680-685. DOI: https://doi.org/10.1038/227680a0

Matkowski A., Tasarz P., Szypuła E. 2008. Antioxidant activity of herb extracts from five medicinal plants from Lamiaceae, subfamily Lamioideae. Journal of Medicinal Plants Research 2 (11): 321-330.

Mogren L., Olsson M., Gertsson U. 2007. Effects of cultivar, lifting time and nitrogen fertiliser level on quercetin content 
in onion (Allium cepa L.) at lifting. Journal of the Science of Food and Agriculture 87 (3): 470-476. DOI: https://doi. org/10.1002/jsfa.2735

Mollavali M., Bolandnazar S., Schwarz D., Rohn S., Riehle P., Nahandi F. 2016. Flavonol glucoside and antioxidant enzyme biosynthesis affected by mycorrhizal fungi in various cultivars of onion (Allium cepa L.). Journal of Agricultural and Food Chemistry 64 (1): 71-77. DOI: https://doi. org/10.1021/acs.jafc.5b04791

Mukherjee S., Bhattacharyyab P., Duttagupta A.K. 2004. Heavy metal levels and esterase variations between metal-exposed and unexposed duckweed Lemna minor: Field and laboratory studies. Environment International 30 (6): 811-814. DOI: https://doi.org/10.1016/j.envint.2004.01.006

Murphy R., Sites J., Buth D., Haufler C. 1996. Proteins I: isozyme electrophoresis. p. 45-126. In: "Molecular Systematics” (D.M. Hillis, C. Moritz, B.K. Mable, eds.). 2nd ed. Sinauer Associates, Sunderland Massachusetts, USA, 655 pp.

Odeyemi I., Afolami S, Sosanya O. 2010. Effect of Glomus mosseae (arbuscular mycorrhizal fungus) on host - parasite relationship of Meloidogyne incognita (southern root-knot nematode) on four improved cowpea varieties. Journal of Plant Protection Research 50 (3): 320-325. DOI: https:// doi.org/10.2478/v10045-010-0055-8

Petkov G. 1995. Nutrition medium for intensive cultivation of green microalgae in fresh and sea water. Archiv für Hydrobiologie 109: 81-85.

Pfeffer H., Dannel F., Römheld V. 1998. Are there connection between phenol metabolism, ascorbate metabolism and membrane integrity in leaves of boron-deficient sunflower plants? Physiologia Plantarum 104 (3): 479-485. DOI: https://doi.org/10.1034/j.1399-3054.1998.1040325.x

Phippen W., Simon J. 2000. Anthocyanin inheritance and instability in purple basil (Ocimum basilicum L.). Journal of Heredity 91 (4): 289-296. DOI: https://doi.org/10.1093/ jhered/91.4.289

Pozo M.J., Cordier C., Dumas-Gaudot E., Gianinazzi S., Barea J.M., Azcón-Aguilar C. 2002. Localized versus systemic effect of arbuscular mycorrhizal fungi on the defence responses to Phytophthora infection in tomato plants. Journal of Experimental Botany 53 (368): 525-534. DOI: https:// doi.org/10.1093/jexbot/53.368.525

Prieto P., Pineda M., Aguilar M. 1999. Spectrophotometric quantitation of antioxidant capacity through the formation of a phosphomolybdenum complex: specific application to the determination of vitamin E. Analytical Biochemistry 269 (2): 337-341. DOI: https://doi.org/10.1006/abio.1999.4019

Pusztahelyi T., Holb I., Pócsi I. 2015. Secondary metabolites in fungus-plant interactions. Frontiers in Plant Science 6: 573. DOI: https://doi.org/10.3389/fpls.2015.00573

Radić S., Pevalek-Kozlina B. 2010. Differential esterase activity in leaves and roots of Centaurea ragusina $\mathrm{L}$. As a consequence of salinity. Periodicum Biologorum 112 (3): 253-258.

Ricci G., Bello M., Caccuri A., Galiazzo F., Federici G. 1984. Detection of glutathione transferase activity on polyacrylamide gels. Analytical Biochemistry 143 (2): 226-230. DOI: https://doi.org/10.1016/0003-2697(84)90657-2

Rozpądek P., Wężowicz K., Stojakowska A., Malarz J., Surówka E., Sobczyk Ł., Anielskaa T., Ważnyd R., Miszalskic Z., Turnau K. 2014. Mycorrhizal fungi modulate phytochemical production and antioxidant activity of Cicho- rium intybus L. (Asteraceae) under metal toxicity. Chemosphere 112: 217-224. DOI: https://doi.org/10.1016/j. chemosphere.2014.04.023

Sahu D., Priyadarshani I., Rath B. 2012. Cyanobacteria - as potential biofertilizer. CIB Tech Journal of Microbiology 1 (2-3): 20-26.

Sakihama Y., Yamasaki H. 2002. Lipid peroxidation induces by phenolics in conjunction with aluminium ions. Biologia Plantarum 45 (2): 249-254. DOI: https://doi.org/10.1023/ A:1015152908241

Šetlik I. 1967. Contamination of algal cultures by heterotrophic microorganisms and its prevention. Annual Report of the Algology for the Year 1966, Trebon, CSAV, Institute of Microbiology: 89-100.

Stuhlfelder C., Mueller M.J., Warzecha H. 2004. Cloning and expression of a tomato cdna encoding a methyl jasmonate cleaving esterase. European Journal of Biochemistry 271 (14): 2976-2983. DOI: https://doi.org/10.1111/j.1432-1033 .2004.04227.x

Tepe B., Sokmen M., Akpulat H.A., Sokmen A. 2006. Screening of the antioxidant potentials of six Salvia species from Turkey. Food Chemistry 95 (2): 200-204. DOI: https://doi. org/10.1016/j.foodchem.2004.12.031

Toussaint J., Smith F., Smith S. 2007. Arbuscular mycorrhizal fungi can induce the production of phytochemicals in sweet basil irrespective of phosphorus nutrition. Mycorrhiza 17 (4): 291-297. DOI: https://doi.org/10.1007/s00572-0060104-3

Toussaint J., St-Arnaud M., Charest C. 2004. Nitrogen transfer and assimilation between the arbuscular mycorrhizal fungus Glomus intraradices Schenck \& Smith and Ri T-DNA roots of Daucus carota L. in an in vitro compartmented system. Canadian Journal of Microbiology 50 (4): 251-260. DOI: https://doi.org/10.1139/w04-009

Wang B., Qiu Y-L. 2006. Phylogenetic distribution and evolution of mycorrhizas in land plants. Mycorrhiza 16 (5): 299-363. DOI: https://doi.org/10.1007/s00572-005-0033-6

Yang J., Meyers K.J., Vander H.J., Liu R. 2004. Varietal differences in phenolic content and antioxidant and anti-proliferative activities of onions. Journal of Agriculture and Food Chemistry 52 (22): 6787-6793. DOI: https://doi.org/10.1021/ jf0307144

Yao M.K., Desilets H., Charles M.T., Boulanger R., Tweddell R.J. 2003. Effect of mycorrhization on the accumulation of rishitin and solavetivone in potato plantlets challenged with Rhizoctonia solani. Mycorrhiza 13 (6): 333-336. DOI: https://doi.org/10.1007/s00572-003-0267-0

Zhishen J., Mengcheng T., Jianming W. 1999. The determination of flavonoid contents in mulberry and their scavenging effects on superoxide radicals. Food Chemistry 64 (4): 555-559. DOI: https://doi.org/10.1016/s0308-8146(98)00102-2

Ziedan E-S. H., Elewa I., Mostafa M., Sahab A. 2011. Application of mycorrhizae for controlling root diseases of sesame. Journal of Plant Protection Research 51 (4): 355-361. DOI: https://doi.org/10.2478/v10045-011-0058-0

Zubek S., Rola K., Szewczyk A., Majewska M., Turnau K. 2015. Enhanced concentrations of elements and secondary metabolites in Viola tricolor L. Induced by arbuscular mycorrhizal fungi. Plant and Soil 390 (1-2): 129-142. DOI: https://doi.org/10.1007/s11104-015-2388-6 